\title{
IMPLEMENTASI MATA KULIAH PAR (PARTICIPATORY ACTION RESEARCH) DI TPQ AL-MAGFIROH DENPASAR BALI
}

Oleh

\author{
Novena Ade Fredyarini Soedjiwo ${ }^{1}$
}

\begin{abstract}
Abstrak
Sebagai tugas akhir mata kuliah PAR, mahasiswa melakukan penelitian langsung ke lapangan untuk mengimplementasikan keilmuan yang telah didapat terpada masyarakat. Mereka melakukan penelitian di TPQ AL-Magfiroh di Denpasar. Kondisi TPQ yang terletak di Mushola Al-Magfiroh telah berdiri sejak tahun 2019 dengan jumlah peserta didik 145 siswa. Penelitian ini menggunakan acuan teori Zuber dan pendekatan metode PAR, dengan tahapan observasi, pengumpulan data, monitoring/aksi, dan evaluasi.

PAR bersifat transformatif dan memberdayakan komunitas lokus penelitian, sehingga menghasilkan program kerja, yaitu mengajar di TPQ tersebut dengan metode Yanbua dan bersama wali murid memberikan semangat pada siswa berupa buku dan alat tulis, pada kegiatan kenaikan jilid. Evaluasi penelitian adalah menemukan kondisi kelas kurang kondusif dan kurangnya tenaga pengajar. Sebagai bahan tindaklanjut, mengkondisikan penambahan dan meningkatkan kualitas tenaga pengajar.
\end{abstract}

\author{
Abstrack \\ IMPLEMENTATION SUBJECT OF PAR \\ (PARTICIPATORY ACTION RESEARCH) \\ IN TPQ AL-MAGFIROH DENPASAR BALI
}

By

Novena Ade Fredyarini Soedjiwo

As a final assignment for PAR subject, students have done conduct research directly into the field to implement the knowledge they have gained in the community. They conducted research at the AL-Magfiroh TPQ in Denpasar. The condition of TPQ which is located in AlMagfiroh Mosque has been established since 2019 with 145 students. This research uses Zuber's theory reference and PAR method approach, with stages of observation, data collection, monitoring / action, and evaluation.

PAR is transformative and empowers the research locus community, so that it produces a work program, which is teaching at the TPQ with the Yanbua method and together with the guardians of students encourages students in the form of books and stationery, on the activities of increasing volumes. The evaluation of the research is finding the condition of the class is less conducive and the lack of teaching staff. As follow-ups are material, condition the addition and increase the quality of the teaching staff.

\footnotetext{
${ }^{1}$ Dosen STAI Denpasar Bali.
} 


\section{Pendahuluan}

Participation Action Research (PAR) merupakan mata kuliah wajib mahasiswa Pendidikan Agama Islam semester V, dengan 3 SKS. Berdasarkan silabus PAR, bahwa mahasiswa dapat melaksanakan praktik lapangan dan laporan hasil. Sebagai tugas akhir dari mata kuliah PAR, mereka melakukan observasi/pengamatan langsung pada subyek dampingan.

Kegiatan partisipasi dalam penelitian menurut Kemmis dan McTaggert (1990: 8), bahwa PAR merupakan penelitian tindakan kegiatan sebagai hasil dari proses penelitian, yaitu penelitian yang diawali dengan merencanakan, melakukan tindakan atau aksi, dan evaluasi dari hasil tindakan. Proses penelitian tersebut merupakan tindakan dalam memahami dan mengubah praktik sosial serta melibatkan praktisi pada tahap-tahap penelitian (MC kernan, 1991:10).

Dengan menggunakan metode PAR, mahasiswa semester V STAI Denpasar melakukan praktik di lapangan. Mereka adalah mahasiswa program studi pendidikan Agama Islam, jumlah mahasiswa dalam mata kuliah PAR adalah 15 orang. Untuk memudahkan dalam praktik, mereka dibagi dalam kelompok dan setiap kelompok terdiri dari 5 orang. Tugas mereka adalah melakukan observasi selama satu bulan di subyek penelitian yang diinginkan, seperti sekolah formal, taman pendidikan Alquran, atau lembaga atau instansi yang berhubungan dengan pengajaran agama Islam. Pilihan tersebut untuk memudahkan mereka dalam mengimplementasikan keilmuan yang telah diperoleh selama mereka belajar di STAI Denpasar.

Mahasiswa memilih untuk melakukan penelitian di Taman Pendidikan Quran (TPQ), mereka berkeinginan, agar dapat mengaplikasikan keilmuan di bidang agama. Dengan berbekal surat izin dari STAI Denpasar mereka dapat melaksanakan penelitian melalui pendekatan observasi dengan metode pembelajaran dalam menerapkan PAR pada TPQ sebagai subyek penelitian.

Melihat pengertian tersebut, maka peran dan keberadaan TPA/TPQ berkesesuaian dengan UU No 20 Tahun 2003 Tentang Sistem Pendidikan Nasional pada Pasal 32 , yang menyebutkan bahwa pendidikan nasional berfungsi mengembangkan kemampuan dan membentuk karakter serta peradaban bangsa yang bermartabat dalam rangka mencerdaskan kehidupan bangsa. Pendidikan nasional bertujuan untuk berkembangnya potensi peserta didik

\footnotetext{
${ }^{2}$ https://www.kompasiana.com/arygunawan/5500dfbda333117c6f5124af/pendidikan-karakter-berbasistaman-pendidikan-al-qur-an-tpa-tpq diakses tanggal 24 Desember 2019.
} 
agar menjadi manusia yang beriman dan bertakwa kepada Tuhan Yang Maha Esa, berakhlak mulia, sehat, berilmu, cakap, kreatif, mandiri, dan menjadi warga negara yang demokratis serta bertanggung jawab. Kesembilan pilar karakter tersebut, terimplementasikan pada proses kegiatan belajar mengajar di Taman Pendidikan Al'Qur'an (TPA/TPQ). Pendidikan yang dilakukan di TPA/TPQ merupakan pendidikan informal dan lebih dominan berorientasi kepada aspek afektif-implementatif dibandingkan aspek kognitif. Pengajar TPA/TPQ disebut dengan ustadz/ustadzah, menyampaikan materi, seperti akhlaq, mengaji, syariah, dan sebisa mungkin dengan penuh pemahaman dan kekeluargaan, jauh berbeda dengan pendidikan formal di sekolah yang hanya menekankan ketuntasan standar nilai tertentu (KKM).

Melalui proses pendidikan seseorang dapat mengetahui apa yang tidak diketahuinya. Sebagaimana wahyu pertama yang diturunkan adalah perintah untuk belajar. Ayat pertama yang diturunkan oleh Allah SWT adalah Surat Al-Alaq, di dalam ayat tersebut Allah SWT memerintahkan kita untuk membaca dan belajar dan memiliki arti:

"Bacalah dengan (menyebut) nama Tuhanmu yang Menciptakan. Dia Telah menciptakan manusia dari segumpal darah. Bacalah, dan Tuhanmulah yang Maha pemurah. Yang mengajar (manusia) dengan perantaran kalam. Dia mengajar kepada manusia apa yang tidak diketahuinya”. (Q.S Al-,,Alaq: 1-5).

Belajar merupakan suatu proses perubahan tingkah laku melalui pendidikan baik secara formal ataupun informal. Melalui proses pembelajaran, seseorang akan mengalami perubahan, dari tidak tahu ,emjadi tahu an berpengalaman. Sehingga pembelajaran yang didapat dapat digunakan untuk menjalani kehidupan manjadi lebih baik dari sebelumnya. Proses pembelajaran tersebut dilakukan dengan beberapa tahapan, seperti kebiasaan seharihari dalam memeroleh pendidikan dan pengetahuan, kecakapan, penerapan, dan evaluasi setelah keilmuan yang diperoleh diterapkan atau ditujukkan sebagai hasil dari pembelajaran dalam pemerolehan pendidikan. Proses pembelajaran merangsang terjadinya interaksi intelektual dalam kognitif, afetif, dan psikomotorik. Keberhasilan program pembelajaran dipengaruhi oleh konteks dalam interaksi pembelajaran, terutama proses pembelajaran dengan menggunakan metode. metode yang digunakan disesuailan dengan konteks kelas atau interaksi pembelajaran.

Taman Pendidikan Al Qur'an (disingkat (TPA/TPQ)) adalah lembaga atau kelompok masyarakat yang menyelenggarakan pendidikan nonformal jenis keagamaan Islam yang bertujuan untuk memberikan pengajaran membaca Alquran sejak usia dini, serta memahami dasar-dasar dinul Islam (keselamatan dan pdrdamaian) pada anak usia taman kanak-kanak, sekolah dasar atau madrasah ibtidaiyah (SD/MI) atau bahkan yang lebih tinggi. TPA/TPQ 
setara dengan RA atau taman kanak-kanak (TK), dengan penekanan kurikulum mengenai dasar-dasar membaca Alquran serta membantu pertumbuhan dan perkembangan rohani anak sebagai persiapan awal dalam memasuki pendidikan selanjutnya.

Salah satu tugas yang telah dilaksanakan oleh Linda dan kawan-kawan, mereka melakukan penelitian di Taman Pendidikan Qur'an (TPQ) Al-Magfiroh Denpasar yang bertempat di Jl. Batas Dukuh Sari Gg. Punglor No. 11 Denapsar Bali. Taman Pendidikan Qur'an (TPQ) Al-Magfiroh berada pada naungan Yayasan Darul Magfiroh Denpasar yang berdiri pada tahun 2009. TPQ ini terletak di tengah-tengah warga muslim, sehingga banyak warga mendaftarkan anak-anak mereka di TPQ tersebut. Sehingga kekurangan tempat untuk belajar mengaji dengan nyaman. Sedangkan jarak dengan tempat TPQ lainnya sekitar $2 \mathrm{~km}$, anak-anak harus diantar oleh orang tua mereka, sedangkan anak-anak yang tinggal di sekitar mushola Al-Magfiroh dapat berjalan kaki, atau bersepeda, serta tidak menyita waktu orang tua mereka untuk mengantarkan mengaji. Sebagian besar orang tua mereka adalah pekerja.

Kegiatan belajar mengaji dan keislaman di TPQ Al-Magfiroh telah berjalan selama 10 tahun, dan telah dikenal oleh warga sekitar. Orangtua warga sekitar merasa bersyukur wilayahnya berdekatan dengan tempat belajar mengaji. Mengingat di Denpasar merupakan warga mayoritas Hindu, pentingnya generasi selanjutnya belajar dan mengenal Alquran. Penguatan keislaman dibutuhkan untuk menjaga ahklak dan akidah seseorang di tengahtengan kehidupan heterogen komunitas non muslim.

Salah satu kelompok tugas mahasiswa memilih lokasi penelitian di Mushola AlMagfiroh, karena diantara mereka mengajar dan tinggal di tempat tersebut. hal tersebut memudahkan mahasiswa melakukan penelitian dan observasi, tanpa meninggalkan perkuliahan mereka. Walaupun observasi yang telah dilakukan belum menunjukan hasil yang signifikan, mereka telah berusaha melebur bersama warga Mushola Al-Magfiroh, agar terlaksana tugas kelompok PAR dan dapat dijadikan laporan tugas akhir mata kuliah tersebut.

\section{Implementasi Metode PAR di Mushola Al-Magfiroh}

Bagian keilmuan yang digunakan untuk mencari dan mendapatkan pengetahuan secara sistematis dan memeroleh bukti fisik, dikatakan sebagai metode. PAR merupakan metode yang digunaka dalam penelitian. Secara harafiah PAR adalah participatory yang memiliki arti paristisipasi atau turut serta, action adalah aksi atau kegiatan, sedangkan research adalah penelitian. Definisi PAR adalah peran serta kegiatan penelitian oleh peneliti dalam subjek penelitian. Menurut Zuber-Skerrit (1991: 2), ada empat tema dasar dalam PAR, yaitu kolaborasi melalui partisipasi, mendapat pengetahuan, dan perubahan sosial. Sedangkan 
proses tersebut diperoleh melalui siklus penelitian tindakan dari empat tahapan, yaitu perencanaan, tindakan, pengamatan dan refleksi. Riset ini dilakukan untuk mengetahui kebiasaan atau kegiatan sekelompok masyarakat tanpa mengkaji dan mengetahui apa yang terjadi serta tanpa memperbaiki tatanan sosial pada subyek penelitian tersebut. Di dalam kegiatan PAR, peneliti/praktisi PAR tidak memisahkan diri dari situasi masyarakat yang diteliti, melainkan melebur ke dalamnya dan bekerja bersama warga dalam melakukan PAR. PAR membahas kondisi masyarakat berdasarkan sistem makna yang berlaku di situ.

Dalam penelitian menggunakan metode PAR bertujuan (1) untuk membangun kesadaran masyarakat atau memberdayakan masyarakat melalui pendidikan kritis dengan berdialog, diskusi publik, dan mengarah pada pembelajaran orang dewasa; (2) untuk mengubah cara pandangn penelitian menjadi sebuah proses partisipasi aktif; dan (3) membawa pada perubahan nilai sosial.

Kelompok tugas PAR yang penulis sajikan adalah hasil laporan dari kelompok I, mereka memahami dan merumuskan mata kuliah PAR di lokasi mereka melakukan penelitian dengan pendekatan PAR. Tahapan awal, mereka merumuskan tahapan kegiatan PAR adalah membuat kelompok kerja PAR dan membuat rencana observasi. Hal tersebut telah menunjukkan bahwa mereka memahami metode awal sebelum pelaksanaan PAR. Kemudian mereka menuyusun daftar pelaksanaan PAR, memudahkan dalam melakukan penelitian di Mushola Al-Magfiroh. Daftar pelaksanaan merupakan rencana obsevasi yang akan dilakukan di lokus penelitian. Pelaksanaan PAR sebagai berikut: (a)Turun ke TPQ AlMagfiroh dan live in; (b) Mendekati kontak atau membangun sekutu strategis; (c) Pengumpulan data melalui observasi dan wawancara; (d) Membuat analisis kasus struktural; (d) Menyusun aksi. Susunan pelaksanaan PAR sudah mendekati kemampuan cara berpikir dalam metode PAR. Dalam pelaksanaan ditekankan bahwa peneliti mengetahui situasi subyek dan dapat melebur di dalamnya, sehingga dapat mempelajari sistem dan membangun kerjasama di antara warga Mushola Al-Magfiroh untuk melakukan perubahan lebih baik dari sebelumnya. Sehingga memudahkan dalam melakukan aksi dalam penelitian bersama warga mushola dan stake holder untuk perubahan.

Dalam observasi mereka mendata jumlah anak-anak mangaji adalah 145 siswa. Jumlah tersebut menunjukkan kurangnya tempat belajar mengaji. Hal tersebut dipengaruhi dengan perizinan membuka kelas TPQ, agak sulit di lingkungan mayoritas non muslim. Dengan jumlah siswa tersebut, menyebabkan interaksi belajar tidak kondusif, serta jumlah pengajar yang masih minim, yaitu tujuh ustad dan ustajah. Para pengajar lulusan dari pesantren di Pasuruan dan mereka masih lulusan setingkat SMU. Kemampuan mereka dalam pengajaran 
telah di tes oleh tim ahli di bidangnya, yaitu ustad lulusan pesantern Pasuruan atas swadaya pengurus yayasan Mushola Al-Magfiroh.

Taman Pendidikan Qur'an (TPQ) Al-Magfiroh dalam metode pendidikan menggunakan Metode Yanbua. Seorang kyai dari pesantren yaitu KH. Arwani Amin (2004) dari Kudus, Jawa Tengah telah menerbitkan buku metode yanbua. Arwani adalah seorang kyai tahfidz Alquran dan nasab gurunya bisa dipertanggungjawabkan sampai ke Rasulullah Muhammad SAW. Menurut Arwani, pembelajaran membaca Al-Qur'an sebaiknya dapat dilakukan sejak dini, yaitu fokus pembinaan Al-Qur'an dengan tilawah wa tahfidz (membaca dan menghafal) karena tilawah dan tahfidz merupakan langkah pertama orang tua dalam pembinaan iman dan Islam pada anak sejak dini.

Metode Yanbua merupakan metode membaca, menulis, dan menghafal Al Quran. Metode tersebut, disusun berdasarkan tingkatan pembelajaran Al Quran yaitu: (a) Mengenal huruf hijaiyah; (b) Membaca kemudian menulis huruf hijaiyah; (c) Mengetahui kaidah atau hukum-hukum membaca Alquran yang disebut tajwid. selain itu dalam kitab Yanbua juga diperkenalkan bacaan alquran dengan tingkat kesulitan atau asing, disebut gharib. Metode Yanbua disusun per jilid, dari tingkat pra TK yaitu jilid satu sampai dengan jilid tujuh. Metode Yanbua disusun berdasarkan tingkatan pembelajaran Al Quran dari mengetahui, membaca serta menulis huruf hijaiyah, kemudian memahami kaidah dan hukum-hukum membaca Al Quran. Dalam mempelajari membaca alquran banyak metode yang digunakan. Menurut pemikiran Arwani, melalui metode yang tepat, memudahkan dalam mengajar, sehingga peserta didik dapat membaca alquran sesuai dengan tajwid. Metode Yanbua merupakan metode pembelajaran membaca, menulis dan menghafal Al-Qur'an, disusun sistematis terdiri 7 jilid, cara membacanya langsung tidak mengeja, cepat, tepat, benar dan tidak putus-putus disesuai dengan makhorijul huruf dan ilmu tajwid.

Mushola Al-Magfiroh telah berdiri sejak 10 tahun memiliki struktur taman pendidikan qoran, sebagai berikut.

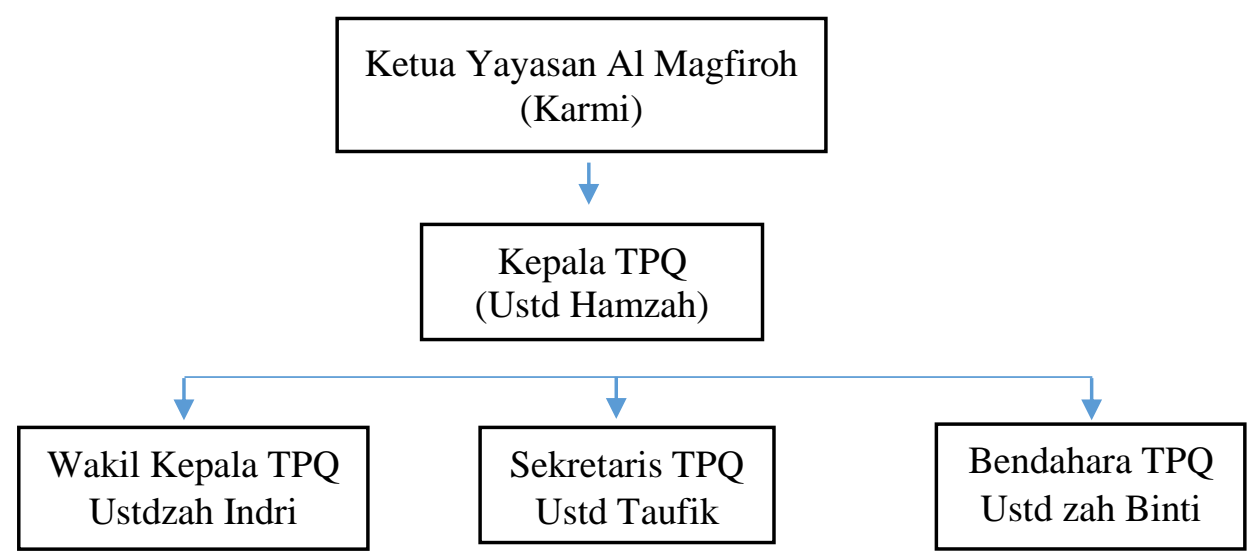


struktur susunan pengurus TPQ tersebut di atas, Hamzah sebagai kepala TPQ, wakilnya Indri, dibantu dengan taufik sebagai sekertaris, dan Binti sebagai bendahara. Walaupun mereka menjabat sebagai pengurus, mereka turut serta mengajar di Mushola Al-Magfiroh. Fungsi pengurus telah dijalankan dan dilaksanakan sesuai dengan bidangnya masing-masing walaupun mereka merangkap sebagai pengajar.

TPQ Al-Magfiroh didirikan pada tahun 2009 dengan berada pada naungan Yayasan Darul Magfiroh. Pada awal berdirinya TPQ Al-Magfiroh menggunakan metode Tilawah dan berganti menjadi Yanbua. Pemilihan metode tersebut dianggap lebih efektif dan siswa mudah menyerap pembelajaran mengaji. Jadwal mengaji TPQ Al-Magfiroh adalah pagi, sore, dan malam. Pilahan tiga jadwal tersebut memudahkan para siswa memilih jadwal, karena siswa sebagian besar sekolah formal. Masing-masing jadwal memiliki ruang kelas yang berbeda, untuk memudahkan pembagian jadwal dan kelas mengaji disajikan pada tabel di bawah ini.

Tabel 2.1 Jadwal dan Pembagian Kelas Mengaji

\begin{tabular}{|l|l|l|}
\hline \multicolumn{1}{|c|}{ Waktu } & \multicolumn{1}{|c|}{ Kelas } & \multicolumn{1}{c|}{ Keterangan } \\
\hline Pagi & 1 kelas & Terdiri dari beberapa jilid. \\
\hline Sore & 4 kelas & Pemula dan jilid 1 -3. \\
\hline Malam & 1 kelas & Jumlah siswa 25 anak \\
\hline
\end{tabular}

Pembagian kelas tersebut berdasarkan kondisi siswa dalam mengikuti pelajaran mengaji. Pada pagi hari, satu kelas diikuti oleh beberapa jilid, dengan dibimbing oleh satu ustad. Sore hari terdiri dari empat kelas dan sisanya di mushola karena keterbatasan kelas. Kelas sore dibimbing oleh lima ustad dan ustadjah. Kelas sore pembelajaran tidak kondusif, karena diikuti oleh 80 siswa, ruangan menjadi sempit dan udara panas, anak-anak sering tidak terkontrol, mereka berlati-larian, ngobrol. Sistem pembelajaran, anak-anak bergilir membaca atau mempraktekan pengucapan di depan ustad atau ustadjah. Mengaji pada malam hari, berjumlah 25 siswa dalam satu kelas dengan pengajar ustad yang bertugas jadwal sore.

Selama observasi yang telah dilaksanakan pada tanggal 2-30 November 2019, oleh mahasiswa STAI Denpasar, mereka mengetahui kondisi masing-masing kelas dan jilid yang telah berjalan di Mushola Al-Magfiroh. Untuk memudahkan dalam memilah kelas dan jilid, penulis menyajikan dalam bentuk tabel di bawah ini. 
Tabel 2.2 Ruang Kelas dan Jilid

\begin{tabular}{|c|c|c|}
\hline Jilid & Pengajar & Jumlah Siswa \\
\hline Pemula & 1 & 20 \\
\hline 1 & 1 & 21 \\
\hline $2-3$ & 1 & 30 \\
\hline 4 & 1 & 20 \\
\hline 5 & 1 & 20 \\
\hline 6 & 6 & 139 \\
\hline Jumlah & 1 & \\
\hline
\end{tabular}

Hasil observasi ruang pemula yang terdiri dari 20 santri dengan pengajar 1 orang, ruang jilid 1 terdiri 21 santri dengan 1 orang pengajar, ruang jilid 2-3 terdiri 28 santri dengan 1 orang pengajar, ruang Jilid 4 terdiri 30 santri dengan 1 orang pengajar, ruang jilid 5 terdiri 20 santri dengan 1 orang pengajar, dan jilid 6 terdiri dari 20 santri dengan 1 orang pengajar. Sisanya mengaji pada waktu malam dan pagi dengan I orang pengajar. Jumlah siswa yang ttedapat dalam tabel 2.2 adalag 136 siswa. Mereka mengaji pada sore hari. Sedangkan sisanya mengaji pada waktu pagi dan malam dengan masing-masing 1 orang pengajar.

Berdasarkan jumlah sisiwa di masing- masing kelas menunjukkan bahwa kelas tersebut penuh dan pembelajaran mengaji tidak kondusif, anak-anak tidak konsentrasi dan focus pada pembelajaran tersebut. Metode mengaji melalui Yanbua, anak-anak membaca cepat dan menulis secara bersama-sama dan siswa secara bergiliran menunjukkan dengan mengaji di depan pengajar. Dengan maksud, pengajar dapat langsung mengetahui kemampuan siswa dalam menyerap dan menghafal Alquran, dan ditulis pada buku penilaian perkembangan atau kemajuan terhadap hafalan siswa. Sehingga pada akhir pembelajaran atau setiap enam bulan sekali ada ujian kenaikan jilid. Untuk kujian kenaikan jilid, diuji oleh pengajar dari ustad dan ustadzah yang mengajar di Mushola Al-Magfiroh.

Selama penyampaian pembelajaran pada siswa, kondisi kelas kurang kondusif, dengan jumlah siswa yang tidak sesuai dengan ruang kelas yang sempit, ruang kelas terasa panas, siswa saling berbicara selama mereka belum mendapat kesempatan mengaji di depan ustad.

Pengajar di TPQ Al-Magfiroh, mengajar di kelas mereka masing-masing, tetapi mereka akan berpindah di kelas lain pada saat kenaikan jilid. Hal tersebut untuk 
meningkatkan kualitas siswa dan pendalaman kemampuan pengajar dalam mengimplementasikan keilmuan. Kenaikan jilid setiap siswa dilakukan setiap enam bulan sekali.

Pada tanggal 08 Desember 2019 diadakan kenaikan jilid. Syarat kenaikan jilid adalah siswa yang telah menyelesaikan jilid 1 dengan menunjukkan kemampuan hafalan dengan benar sesuai tajwid dihadapan [engajar di ruangan kelas masing-masing sesuai dengan jilid dan kelas mereka. Kenaikan jilid di TPQ Al-Magfiroh di tes oleh kepala TPQ Al-Magfiroh, yaitu Ustad Hamzah. Sedangkan siswa yang tidak mengikuti evaluasi dan tes kenaikan jilid, mereka tetap melakukan pembelajaran mengaji seperti biasa. Sedangkan bagi kualitas sumber daya manusia yang mengajar di TPQ A-lMagfiroh, mereka mendapat kesempatan pendidikan di Pasuruan secara bergantian dengan biaya ditanggung oleh Yayasan. Pendidikan tersebut dilakukan setiap setahun sekali. Sehingga kualitas dan kemampuan pengajar sesuai dengan target, visi, dan misi yayasan Al-Magfiroh.

Mahasiswa STAI Denpasar ikut serta dalam memberikan pembelajaran mengaji dan memberikan saran atau solusi terhadap situasi kelas dan jumlah siswa, yaitu bahwa setiap kelas kurang memiliki guru dalam mengajar, karena kelas yang kurang luas. Jumlah siswa 30 dalam ruangan kelas, dengan 1 orang pengajar. Saran dan solusi terhadap kondisi tersebut, dalam satu kelas sebaiknya ada 2 pengajar dalam satu kelas, sehingga santri tidak fokus dalam mengaji dan desak-desakan. Selain itu menyarankan untuk menambah Guru ngaji tetapi hasil wawancara dengan kepala TPQ yaitu Ustad Hamzah "untuk menambah guru ngaji harus menunggu keputusan Yayasan itu sendiri”. Saran dan masukan dari mahasiswa STAI Denpasar tergantung dari ketua yayasan Al-Magfiroh. Sebagai tindak lanjut dari penelitian tersebut, mahasiswa STAI Denpasar, diberi kesempatan untuk mengajar di TPQ tersebut serta ada keinginan untuk mengajukan penambahan pengajar pada yayasan Al-Magfiroh.

Kinerja mahasiswa STAI Denapasar dalam melaksanakan penelitian dengan pendekatan, sudah menunjukkan kepemahaman dalam menerima mata kuliah PAR, hal tersebut terlihat pada laporan yang menjelaskan hasil dari observasi, kemudian mereka melakukan aksi dengan melebur dan menjadi tenaga pengajar dengan menggunakan metode stick, membantu ustad di TPQ tersebut. Pengajar di TPQ Al-Magfiroh belum mengenal metode tersebut, mereka belajar bersama menerapkan pada siswa yang belajar mengaji. Mahasiswa STAI Denpasar berperan aktif dan diterima baik dengan warga mushola AlMugfiroh. Disamping itu hasil kerja mereka dengan stakeholder, tampak pada saat acara kenaikan jilid. Pada acara tersebut, mahasiswa beserta wali murid, selaku stake holder, 
memberikan hadiah dan door price pada siswa, berupa buku tulis. Kemudian mahasiswa memberikan kenang-kenangan berupa plakat pada Ketua TPQ Al-Mugfiroh.

\section{Kesimpulan}

Participatory Action Research (PAR) adalah metode riset yang dilaksanakan secara partisipatif di antara warga masyarakat dalam suatu komunitas aras bawah yang semangatnya untuk mendorong terjadinya aksi-aksi transformatif melakukan pembebasan masyarakat dari belenggu ideologi dan relasi kekuasan (perubahan kondisi hidup yang lebih baik). Dengan demikian, sesuai istilahnya PAR memiliki tiga pilar utama, yakni metodologi riset, dimensi aksi, dan dimensi partisipasi. Artinya, PAR dilaksanakan dengan mengacu metodologi riset tertentu, harus bertujuan untuk mendorong aksi transformatif, dan harus melibatkan sebanyak mungkin masyarakat warga atau anggota komunitas sebagai pelaksana PAR-nya sendiri.

Taman Pendidikan Qur'an (TPQ) Taman Pendidikan Al Qur'an (disingkat TPQ/TPA) adalah lembaga atau kelompok masyarakat yang menyelenggarakan pendidikan nonformal jenis keagamaan Islam yang bertujuan untuk memberikan pengajaran membaca Al Qur'an sejak usia dini, serta memahami dasar-dasar dinul Islam pada anak usia taman kanak-kanak, sekolah dasar dan atau madrasah ibtidaiyah (SD/MI) atau bahkan yang lebih tinggi. TPQ AlMagfiroh didirikan pada tahun 2009 dengan berada pada naungan Yayasan Darul Magfiroh, TPQ Al-Magfiroh memiliki 145 santri yang mengaji. Metode yang dipakai saat awal berdiri adalah Tilawah dan berganti menjadi Yanbua karena di nilai lebih efektif.

Program kerja yang dihasilkan yaitu mengajar di TPQ tersebut dan bersama wali murid memberikan semangat pada siswa berupa buku dan alat tulis pada saat kenaikan jilid. Hasil evaluasi penelitian adalah menemukan kondisi kelas kurang kondusif dan kurangnya tenaga pengajar. Sebagai bahan tindaklanjut, mengkondisikan penambahan dan meningkatkan kualitas tenaga pengajar.

Melihat antusias mahasiswa terjun langsung ke lapangan, dapat menambah wawasan dan dan mengenal beberapa metode pembelajaran pada penyampaian materi belajar Alquran serta menambah pengalaman bagi mereka dalam berinteraksi sosial. Mengingat siswa sekarang lebih aktif dan kreatif akibat perkembangan tekhnologi, sehingga berpengaruh dalam menyerap pembelajaran Alquran, perlunya wawasan dalam bentuk sosialisasi, dialog, diskusi antar kelompok dengan bidang keilmuan yang berkaitan. Sehingga mampu 
memberikan yang terbaik dari sebelumnya. Selain itu menjadi acuan dan referensi bagi akademisi, lembaga sosial dan pemerhati pendidikan karakter anak.

\section{DAFTAR PUSTAKA}

Arif, Arifuddin. 2008. Pengantar Ilmu Pendidikan Islam. Jakarta: Kultura.

Arwani, Ulil Albab. 2004. Thoriqoh Baca Tulis dan Menghafal Al Quran Yanbu'a. Kudus: Pondok Tahfidh.

Kemmis,S., and McTaggert, R., (1990). The Action Research Planner. Geelong: Deakin University Press.

McKernan,J., (1991). Curriculum Action Research: A Handbook of Methods and Resources for the Reflective Practitioner. London: Kogan Page.

Zuber-Skerrit. (1992). Improving Learning and Teaching Through Action Learning and Action Research Draft paper for the HERDSA Conference 1992 University of Queensland.

https/www.bantuanhukumor.idweb/participatory.action-research-par/diakses pada tanggal 13 Desember 2019 pukul 11.04 WITA 